\title{
Erratum to: Surgeon perception is not a good predictor of peri-operative outcomes in robot-assisted radical prostatectomy
}

\author{
Joshua Stern - Saurabh Sharma - Noemi Alice Spinazzi - Pierre Mendoza • \\ Mary Walicki · Rachel Hastings · Kelly Monahan • Baber Sheikh • \\ Alexei Wedmid · David I. Lee
}

Published online: 13 August 2011

(C) Springer-Verlag London Ltd 2011

Erratum to: J Robotic Surg

DOI 10.1007/s11701-011-0293-4

Unfortunately, the author Noemi Alice Spinazzi was omitted in the original version of this article. Her name and affiliation are shown here.

Noemi Alice Spinazzi

Perelman School of Medicine,

University of Pennsylvania, Philadelphia, PA, USA

e-mail: spinazzi@gmail.com

The correct order of authors is:

Joshua Stern · Saurabh Sharma · Noemi Alice Spinazzi · Pierre Mendoza · Mary Walicki · Rachel Hastings · Kelly Monahan · Baber Sheikh · Alexei Wedmid · David I. Lee

The online version of the original article can be found under doi:10.1007/s11701-011-0293-4.

J. Stern - S. Sharma - P. Mendoza - M. Walicki - R. Hastings ·

K. Monahan · B. Sheikh · A. Wedmid · D. I. Lee ( $₫)$

Division of Urology, Penn Presbyterian Medical Center,

University of Pennsylvania, 51 North 39th Street,

Medical Office Building Suite 300,

Philadelphia, PA 19104, USA

e-mail: david.i.lee@uphs.upenn.edu

N. A. Spinazzi

Perelman School of Medicine,

University of Pennsylvania, Philadelphia, PA, USA

e-mail: spinazzi@gmail.com 